\title{
Hubungan Faktor Fisik Lingkungan Terhadap Keanekaragaman Dan Dominansi Echinodermata Di Zona Intertidal Sekitar Dermaga Desa Hila Pulau Romang Kabupaten Maluku Barat Daya
}

\author{
Sriyanti I A Salmanu ${ }^{1}$, Ine Arini ${ }^{2}$ \\ FKIP Unpatti, Ambon \\ E-mail: sriyanti_salmanuk@yahoo.co.id
}

\begin{abstract}
Abstrak: Faktor fisik kimia lingkungan merupakan salah satu factor yang mempengaruhi keberadaan organisme pada suatu daerah perairan. Berdasarkan penelitian pada 10 transek dengan 50 plot pengamatan kondisi factor fisik kimia ketika dilakukan pengukuran adalah sebagai berikut; rata-rata pengukuran suhu $27,7{ }^{0} \mathrm{C}, \mathrm{pH} 6,36$, salinitas 4,9 \%o, dan Oksigen terlarut 5,9 mg/L. Indeks keanekaragaman echinodermata adalah 1,865 , nilai ini mengindikasikan bahwa indeks keanekaragaman echinodermata pada lokasi penelitian sedang, indeks kemerataannya adalah 0,789, nilai ini mengindikasikan bahwa kemerataan echinodermata penelitian rendah, pada lokasi penelitian sangat jauh berbeda atau tidak merata, indeks kekayaannya adalah 62,033 ini mengindikasikan kekayaan echinodermata rendah. Nilai rata-rata dominanasinya adalah 0,032 masuk dalam kategori rendah. Hubungan factor fisik kimia lingkungan terhadap keanekaragaman terlihat bahwa nilai korelasi adalah 1,013 dan ketika dilakukan uji lanjut menggunakan uji $\mathrm{t}$, maka terlihat bahwa $\mathrm{t}$ hitung 10,90 $>\mathrm{t}$ table 2,015 maka dapat disimpulkan bahwa ada hubungan yang signifikan antara factor fisik kimia lingkungan dengan keanekaragaman. Hubungan factor fisik kimia lingkungan terhadap dominanasi echinodermata terlihat bahwa nilai korelasi adalah 5,127 dan ketika dilakukan uji lanjut menggunakan uji $\mathrm{t}$, maka terlihat bahwa $\mathrm{t}_{\text {hitung }} 1,731<\mathrm{t}_{\text {table }} 2,015$ maka dapat disimpulkan bahwa tidak ada hubungan yang signifikan antara factor fisik kimia lingkungan dengan dominanasi echinodermata.
\end{abstract}

\section{Kata Kunci: Echinodermata, Faktor Fisik, Keanekaragaman, Kepadatan}

Hewan yang masuk dalam filum Echinodermata sebarannya hampir di seluruh perarairan Indonesia (Suartima K, 2017). Anggota dari filum echinodermata ini diklasifikasikan atas 5 kelas yaitu Asteroidea, Ophiuroidea, Echinoidea, Holonthuroidea dan Cnidaria dan seluruhnya hidup di laut. Romimohtarto \& Juwana, 1999). Echinodermata menjadi salah satu hewan yang sangat penting dalam ekosistem laut karena hewan ini dapat bermanfaat dalam rantai makanan, karena hewan ini menjadi pemakan sampah organik dan hewan kecil lainnya. Hernandez et al (2006 dalam Angreni F dkk, 2017) mengungkapkan bahwa Echinodermata memiliki sifat pemakan seston atau pemakan destritus yang membantu 
merombak sisa-sisa bahan organic yang sudah tidak terpakai oleh organism lain, tetapi masih dapat dimanfaatkan oleh beberapa Echinodermata.

Pada ekosistem terumbu karang Echinodermata mempunyai peranan penting pada jaringan makanannya, dan perannya sebagai herbivora, carnivora, omnivora ataupun sebagai pemakan detritus (Clark \& Rowe, 1971; Birkeland, 1989; Best, 1994 dalam Yusron E, 2010). Selain itu, kelompok Echinodermata juga sebagai sumber makanan bagi biota yang hidup di ekosistem terumbu karang (Yusron E, 2010). Selain Echinodermata mampu hidup pada ekosistem terumbu karang, hewan ini juga banyak ditemukan pada ekosistem padang lamun yang memiliki factor fisik kimia lingkungan yang mendukung keberadannya.

Factor fisik kimia lingkungan suatu perairan pantai mampu memberi kontribusi yang penting bagi keanekaragaman dan dominansi jenis hewan yang hidup dilokasi tersebut demikian juga dengan jenis-jenis hewan Echinodermata. Keberadaan Hewan Echinodermata di suatu perairan pantai mungkin saja berhubungan dengan factor fisik kimia lingkungan perairan pantai tersebut. Pada daerah perairan pantai di sisi kiri dan kanan Dermaga Kapal Desa Hila Pulau Romang Kabupaten Maluku Barat Daya memiliki padang lamun yang cukup luas yang berbatasan dengan hutan mangrove. Sebelum dibuat dermaga kapal, banyak ditemukan hewan Echinodermata di daerah ini dan untuk mengetahui keberadaannya saat ini maka dilakukan penelitian untuk mengetahui hubungan factor lingkungan terhadap keanekaragaman dan dominansi Echinodermata.

\section{METODE PENELITIAN}

Penelitian ini dilakukan pada zona intertidal desa Hila Pulau Romang kabupaten Maluku Barat Daya pada bulan September 2017. Lokasi pengambilan sampel tepat di samping kiri dan kanan dermaga desa Hila, dimana pengambilan contoh biota Echinodermata pada lokasi menggunakan metoda transek kuadrat. Dimana tali transek ditarik tegak lurus dari posisi titik zona intertidal tengah (daerah yang masih tergenang air ketika air surut) sampai kearah surut terendah sepanjang 50 meter, dengan plot pengamatan (sampling) dari frame kayu berukuran 1 x $1 \mathrm{~m}$. Titik plot pengamatan dilakukan tiap jarak 10 meter sepanjang garis transek dan jarak transek satu dengan transek ke dua 20 meter. Setiap fauna Echinodermata yang terdapat dalam kerangka frame tersebut dicatat jumlah jenis dan jumlah individunya.

Keanekragaman Echinodermata, dianalisis secara diskriptif dengan menggunakan rumus indeks keanekaragaman Shannon-Wiener, sebagai berikut.

$\mathrm{H}^{\prime}=-\sum$ Pi ln Pi di mana

$\mathrm{Pi}=$ ni/n (Ludwig \& Reynolds, 1988 dalam Rumahlatu D. dkk, 2008).

Besarnya indeks keanekaragaman jenis menurut Shannon Wienner didefinisikan sebagai berikut:

a. Nilai ' $H>3$ menunjukan bahwa keanekaragaman echinodermata pada suatu transek adalah melimpah tinggi.

BIOLOGI SEL (VOL 8 NO 2 EDISI JUL-DES 2019 ISSN 2252-858X/E-ISSN 2541-1225) PAGE 184 
b. Nilai ' $H 1 \leq$ ' $H \leq 3$ menunjukan bahwa keanekaragaman echinodermata pada transek adalah sedang melimpah.

c. Nilai ' $H<1$ menunjukan bahwa keanekaragaman echinodermata pada suatu transek adalah sedikit atau rendah.

Untuk perhitungan indekks dominansi digunakan rumus berikut:

$$
\begin{aligned}
& \text { ID }=\boldsymbol{\Sigma}(\mathbf{n} . \mathbf{i} / \mathbf{N}) \mathbf{2} \\
& \text { Keterangan: } \\
& \text { ID = indeks dominansi } \\
& \text { n.i = nilai penting tiap spesies ke- } \mathrm{i} \\
& \mathrm{N}=\text { total nilai penting }
\end{aligned}
$$

Tabel 1. Kategori Indeks Dominansi

\begin{tabular}{|l|l|}
\hline \multicolumn{1}{|c|}{ Dominansi } & \multicolumn{1}{c|}{ Kategori } \\
\hline $0,00<\mathrm{C} \leq 0,50$ & Rendah \\
\hline $0,50<\mathrm{C} \leq 0,75$ & Sedang \\
\hline $0,75<\mathrm{C} \leq 1,00$ & Tinggi \\
\hline
\end{tabular}

Sumber: Rappe (2010 dalam Arifah D, dkk 2017)

Untuk mengetahui hubungan faktor fisik-kimia lingkungan (suhu, salinitas, $\mathrm{pH}$ dan DO) terhadap keanekaragaman Echinodermata di pantai Lokasi pengambilan sampel tepat di samping kiri dan kanan dermaga desa Hila, dihitung dengan analisis regresi ganda pada taraf uji $0,05 \%$.

\section{HASIL DAN PEMBEHASAN}

\section{Data Faktor Lingkungan}

Berdasarkan hasil penelitian pada 10 transek dengan 50 plot pengamatan kondisi factor fisik kimia ketika dilakukan pengukuran adalahs ebagai berikut; rata-rata pengukuran suhu $27,7^{\circ} \mathrm{C}$, rata-rata nilai $\mathrm{pH}$-nya adalah 6,36, rata-rata nilai Salinitas-nya 4,9 \%o, dan rata-rata Oksigen terlarutnya adalah 5,9 mg/l. Pengukuran faktor lingkungan ini dilakukan bersamaan dengan pengumpulan data jenis Echinodermata. Data hasil pengukuran faktor fisik kimia lingkungan dapat di lihat pada table 2.

Tabel 2. Hasil pengukuran factor fisik kimia lingkungan perairan pantai desa Hila.

\begin{tabular}{|c|l|c|c|c|c|c|c|c|c|c|c|c|}
\hline \multirow{2}{*}{$\begin{array}{l}\text { N } \\
\mathbf{0}\end{array}$} & $\begin{array}{l}\text { Paramet } \\
\text { er Fisika } \\
\text { / Kimia }\end{array}$ & \multicolumn{6}{|c|}{ Rata-Rata Pengukuran Factor Lingkungan Pada Tiap Transek } & $\begin{array}{c}\text { Rata- } \\
\text { rata }\end{array}$ \\
\cline { 3 - 13 } & $\mathbf{1}$ & $\mathbf{2}$ & $\mathbf{3}$ & $\mathbf{4}$ & $\mathbf{5}$ & $\mathbf{6}$ & $\mathbf{7}$ & $\mathbf{8}$ & $\mathbf{9}$ & $\mathbf{1 0}$ & \\
\hline $\mathbf{1}$ & $\begin{array}{l}\text { Suhu air } \\
\left({ }^{\circ} \mathrm{C}\right)\end{array}$ & 27 & 27 & 27 & 28 & 28 & 27 & 28 & 27 & 29 & 30 & $\begin{array}{c}27,7 \\
\circ\end{array}$ \\
\hline $\mathbf{2}$ & $\mathrm{pH}$ air & 6,34 & 6,35 & 6,35 & 6,36 & 6,36 & 6,35 & 6,37 & 6,36 & 6,38 & 6,40 & 6,36 \\
\hline $\mathbf{3}$ & Salinitas & 4,8 & 4,9 & 4,7 & 5 & 5 & 4,9 & 5 & 4,8 & 5 & 4,9 & $\begin{array}{c}4,9 \\
\%\end{array}$ \\
\hline $\mathbf{4}$ & $\begin{array}{l}\text { Oksigen } \\
\text { terlarut }\end{array}$ & 5,8 & 5,9 & 5,7 & 6 & 6 & 5,9 & 6 & 6,1 & 6 & 6,4 & $\begin{array}{c}5,9 \\
\mathrm{mg} / 1\end{array}$ \\
\hline
\end{tabular}


Romimohtarto \& Juana, (1999) mengungkapkan bahwa suhu alami air laut berkisar antara suhu dibawah $0^{\circ} \mathrm{C}-33^{\circ} \mathrm{C}$ dan perubahan suhu dapat memberi pengaruh besar terhadap sifat-sifat air laut dan termasuk biota laut. Nilai $\mathrm{pH}$ pada zona intetrtidal suatu perairan, sangat mempengaruhi keberadaan jenis Echinodermata. Kisaran pH normal untuk kehidupan suatu makhluk hidup pada zona intertidal berkisar antara 7,5-8,4 (Nybakken, 1992 dalam Rumahlatu D. dkk, 2008). Soemodhiharjo (1990 dalam Rumahlatu D, 2008) mengungkapkan bahwa faktor fisik-kimia laut meliputi salinitas, $\mathrm{pH}$, arus, suhu, dan kecerahan yang selalu berubah-ubah sangat berpengaruh terhadap kehidupan organisme di daerah pasang surut. Berdasarkan hasil penelitian rata-rata pengukuran suhu $27,7^{\circ} \mathrm{C}$, rata-rata nilai $\mathrm{pH}$-nya adalah 6,36 , rata-rata nilai Salinitas-nya 4,9\%o, dan ratarata Oksigen terlarutnya adalah $5,9 \mathrm{mg} / \mathrm{l}$, maka dapat dikatakan bahwa rata-rata nilai pengukuran factor lingkungan ini masih dapat ditoleransi hewan Echinodermata untuk hidup ketika hewan ini berada di lokasi penelitian, karena kondisi ini sewaktu-waktu dapat berubah.

\section{Data Keanekaragaman}

Dari hasil penelitian ditemukan 6 jenis Echinodermata yaitu jenis Echinometra mathaei, Protoreaster nodosus, Archaster angulatus, Holothuria atra, dan Holothuria axiolonga. Untuk indeks keanekaragaman pada lokasi penelitian dapat dilihat pada tabel 3 di bawah ini.

Tabel 3. Ringkasan Data keanekaragaman echinodermata pada lokasi penelitian.

\begin{tabular}{|c|c|c|c|c|c|c|c|c|c|c|}
\hline No & $\begin{array}{c}\text { Nama } \\
\text { Spesies }\end{array}$ & $\mathbf{N i}$ & $\mathbf{N}$ & $\mathrm{ni} / \mathbf{N}$ & $\ln n i / N$ & $\overline{\mathbf{H}^{\prime}}$ & $\begin{array}{c}\mathrm{H}^{\prime} \\
\text { maks }\end{array}$ & $\mathbf{E}$ & $\sqrt{n}$ & $\bar{R}$ \\
\hline 1 & $\begin{array}{l}\text { Diadema } \\
\text { antillarum }\end{array}$ & 13 & 64 & $\begin{array}{c}0.20 \\
3\end{array}$ & -1.594 & 1.594 & 2.364 & 0.674 & 3.606 & 17.748 \\
\hline 2 & $\begin{array}{l}\text { Echinometr } \\
\text { a mathaei }\end{array}$ & 19 & 64 & $\begin{array}{c}0.29 \\
7\end{array}$ & -1.214 & 1.214 & 2.364 & 0.513 & 4.359 & 14.682 \\
\hline 3 & $\begin{array}{l}\text { Protoreaster } \\
\text { nodosus }\end{array}$ & 8 & 64 & $\begin{array}{c}0.12 \\
5\end{array}$ & -2.079 & 2.079 & 2.364 & 0.879 & 2.828 & 22.631 \\
\hline 4 & $\begin{array}{l}\text { Archaster } \\
\text { angulatus }\end{array}$ & 10 & 64 & $\begin{array}{c}0.15 \\
6\end{array}$ & -1.858 & 1.858 & 2.364 & 0.786 & 3.162 & 20.240 \\
\hline 5 & $\begin{array}{l}\text { Holothuria } \\
\text { atra }\end{array}$ & 6 & 64 & $\begin{array}{c}0.09 \\
4\end{array}$ & -2.364 & 2.364 & 2.364 & 1 & 2.449 & 26.133 \\
\hline 6 & $\begin{array}{l}\text { Holothuria } \\
\text { axiolonga }\end{array}$ & 8 & 64 & $\begin{array}{c}0.12 \\
5\end{array}$ & -2.079 & 2.079 & 2.364 & 0.879 & 2.828 & 22.631 \\
\hline \multicolumn{6}{|c|}{ Jumlah } & 11.188 & & 4.731 & & 124.065 \\
\hline \multicolumn{6}{|c|}{ Nilai Rata-rata } & 1.865 & & 0.789 & & 62.033 \\
\hline
\end{tabular}

Indeks keanekaragaman jika $1<\mathrm{H}^{\prime}<2$ maka keanekaragaman sedang. Berdasarkan perhitungan indeks keanekaragaman echinodermata yang disajikan pada table 2 di atas terlihat bahwa, rata-rata indeks keanekaragaman adalah 1,865, nilai ini mengindikasikan bahwa indeks keanekaragaman echinodermata pada zona intertidal desa Hila Kabupaten Maluku Barat Daya khusunya pada lokasi penelitian sedang. Rata-rata 
indeks kemerataannya adalah 0,789, nilai ini mengindikasikan bahwa kemerataan echinodermata pada lokasi penelitian rendah, artinya bahwa kemerataan individu yang dimiliki pada lokasi penelitian sangat jauh berbeda. Dan rata-rata indeks kekayaannya adalah 62,033 ini mengindikasikan kekayaan echinodermata rendah. Arifah D, dkk (2017) menyatakan bahwa suatu komunitas dikatakan memiliki indeks keanekaragaman tinggi apabila pada komunitas tersebut tersusun atas banyak spesies dengan kelimpahan spesies yang sama atau hampir sama. Berdasarkan hasil penelitian kekayaan dan kemerataan Echinodermata rendah mengakibatkan keanekaragaman pada lokasi penelitian rendah.

\section{Data Dominansi}

Ringkasan data hasil penelitian dominansi dapat dilihat pada tabel 4

Tabel 4. Ringkasan data nilai dominansi pada lokasi penelitian

\begin{tabular}{|c|l|l|l|c|}
\hline No & \multicolumn{1}{|c|}{ Nama Spesies } & Ni & N & C \\
\hline 1 & Diadema antillarum & 13 & 64 & 0,041 \\
\hline 2 & Echinometra mathaei & 19 & 64 & 0,088 \\
\hline 3 & Protoreaster nodosus & 8 & 64 & 0,016 \\
\hline 4 & Archaster angulatus & 10 & 64 & 0,024 \\
\hline 5 & Holothuria atra & 6 & 64 & 0,008 \\
\hline 6 & Holothuria axiolonga & 8 & 64 & 0,016 \\
\hline \multicolumn{5}{|r|}{ Jumlah } \\
\hline \multicolumn{4}{|r|}{ Nilai Rata-rata } & $\mathbf{0 , 1 9 3}$ \\
\hline
\end{tabular}

Dari data hasil pengamatan dan hasil perhitungan dominansi echinodermata pada zona intertidal desa Hila kabupaten Maluku Barat Daya, nilai rata-rata dominanasinya adalah 0,032. Menurut Rappe (2010 dalam Arifah D, dkk 2017) mengungkapakan bahwa indeks $0,00<\mathrm{C} \leq 0,50$ masuk dalam kategori rendah. Berdasarkan rujukankan tersebut maka indeks dominansi pada lokasi penelitian masuk dalam kategori rendah. Rendahnya indeks dominansi disebabakan karena adanya spesies yang mendominanasi atau ditemukan lebih banyak di lokasi penelitian adalah Echinometra mathaei dengan jumlah individu 19 dan nilai dominansinya adalah 0,088.

\section{Hubungan Keanekaragaman Dengan Factor Lingkungan}

Untuk melihat hubungan factor fisik kimia lingkungan terhadap keanekaragaman maka dilakukan uji regresi ganda, ringkasan hasil analisisnya dapat dilihat pada tabel 5 .

Tabel 5. Ringkasan data hubungan faktorfisik kimia lingkungan terhadap keanekaragaman echinodermata

\begin{tabular}{|c|c|c|c|c|c|c|}
\hline $\mathrm{X}$ & $\begin{array}{l}\text { Rata- } \\
\text { rata X }\end{array}$ & $\begin{array}{c}\mathrm{Y} \\
\text { (keanekaragaman) }\end{array}$ & $\mathrm{XY}$ & RY & $\mathrm{t}_{\text {hitung }}$ & $\mathrm{t}_{\text {table }}$ \\
\hline Suhu & $27,7^{\circ} \mathrm{C}$ & \multirow{4}{*}{1,865} & 51,661 & \multirow{4}{*}{1,013} & \multirow{4}{*}{10,90} & \multirow{4}{*}{2,015} \\
\hline $\mathrm{pH}$ air & 6,36 & & 11,861 & & & \\
\hline Salinitas & $4,9 \%$ & & 9.139 & & & \\
\hline $\begin{array}{l}\text { Oksigen } \\
\text { terlarut }\end{array}$ & $5,9 \mathrm{mg} / \mathrm{l}$ & & 11,004 & & & \\
\hline
\end{tabular}

BIOLOGI SEL (VOL 8 NO 2 EDISI JUL-DES 2019 ISSN 2252-858X/E-ISSN 2541-1225) PAGE 187 


\section{3,63}

Hasil analisis hubungan factor fisik kimia lingkungan terhadap keanekaragaman terlihat bahwa nilai korelasi atau RY-nya adalah 1,013 dan ketika dilakukan uji lanjut menggunakan uji $\mathrm{t}$, maka terlihat bahwa $\mathrm{t}$ hitung 10,90 $>\mathrm{t}$ table 2,015 maka dapat disimpulkan bahwa ada hubungan yang signifikan antara factor fisik kimia lingkungan dengan keanekaragaman. Suhu, $\mathrm{pH}$, salinitas dan oksigen terlarut merupakan factor fisik kimia lingkungan yang kondisinya sangat berpengaruh terhadap keberadaan Echinodermata pada lokasi penelitian.Nybakken (1986), mengungkapkan bahwa kebanyakan organism litoral menunjukan toleransi yang terbatas terhadap salinitas dan factor lingkungan lainnya.

\section{Hubungan factor fisik kimia lingkungan dengan dominansi}

Untuk melihat hubungan factor fisik kimia lingkungan terhadap dominansi maka dilakukan uji regresi ganda, ringkasan hasil analisisnya dapat dilihat pada tabel 6.

Tabel 6 Ringkasan data hubungan faktorfisik kimia lingkungan terhadap kepadatan echinodermata

\begin{tabular}{|c|c|c|c|c|c|c|}
\hline $\mathrm{X}$ & Rata-rata X & $\begin{array}{c}\mathrm{Y} \\
\text { (dominanasi) }\end{array}$ & $\mathrm{XY}$ & $\mathrm{RY}$ & t hitung & t table \\
\hline Suhu & $27,7^{\circ} \mathrm{C}$ & \multirow{4}{*}{0,032} & 0,886 & \multirow{4}{*}{5,127} & \multirow{4}{*}{1,731} & \multirow{4}{*}{2,015} \\
\hline $\mathrm{pH}$ air & 6,36 & & 0,204 & & & \\
\hline Salinitas & $4,9 \%$ & & 0,157 & & & \\
\hline $\begin{array}{l}\text { Oksigen } \\
\text { terlarut }\end{array}$ & $5,9 \mathrm{mg} / \mathrm{l}$ & & 0,189 & & & \\
\hline & & & 1,36 & & & \\
\hline
\end{tabular}

Hasil analisis hubungan factor fisik kimia lingkungan terhadap dominanasi echinodermata terlihat bahwa nilai korelasi atau RY-nya adalah 5,127 dan ketika dilakukan uji lanjut menggunakan uji $\mathrm{t}$, maka terlihat bahwa $\mathrm{t}$ hitung $1,731<\mathrm{t}$ table 2,015 maka dapat disimpulkan bahwa tidak ada hubungan yang signifikan antara factor fisik kimia lingkungan dengan dominanasi echinodermata. Hasil analisis penelitian ini ternyata tidak ada hubungan factor fisik kimia lingkungan terhadap dominanasi echinodermat disebabakan karena, dominansi Echinodermata pada suatu daerah perairan pantai tidak ditentukan oleh factor lingkungan. Leksono (2007 dalam Rumahlatu D, dkk 2008) menungkapkan bahwa pola penyebaran menggambarkan posisi suatu spesies berdasarkan pergerakan dan perpindahannya. Distribusi dari suatu individu mungkin dibatasi oleh faktor perilaku pemilihan habitatnya. Sehingga dapat dikatakan bahwa factor fisik kimia lingkungan tidak mempengaruhi dominansi Echinodermata karena kemampuan hewan ini untuk berpindah tempat.

\section{KESIMPULAN}

1. Nilai rata-rata indeks keanekaragaman adalah 1,865 , nilai ini mengindikasikan bahwa indeks keanekaragaman echinodermata sedang. Rata-rata indeks kemerataannya 
adalah 0,789, nilai ini mengindikasikan bahwa kemerataan echinodermata rendah, artinya bahwa kemerataan individu yang dimiliki pada lokasi penelitian sangat jauh berbeda. Dan rata-rata indeks kekayaannya adalah 62,033 ini mengindikasikan kekayaan echinodermata rendah. hubungan factor fisik kimia lingkungan terhadap keanekaragaman terlihat bahwa nilai korelasi atau RY-nya adalah 1,013 dan ketika dilakukan uji lanjut menggunakan uji $t$, maka terlihat bahwa $t_{\text {hitung }} 10,90>t$ table 2,015 maka dapat disimpulkan bahwa ada hubungan yang signifikan antara factor fisik kimia lingkungan dengan keanekaragaman.

2. Nilai rata-rata dominanasinya adalah 0,032 masuk dalam kategori rendah. Hubungan factor fisik kimia lingkungan terhadap dominanasi echinodermata terlihat bahwa nilai korelasi atau RY-nya adalah 5,127 dan ketika dilakukan uji lanjut menggunakan uji $\mathrm{t}$, maka terlihat bahwa $\mathrm{t}_{\text {hitung }} 1,731<\mathrm{t}_{\text {table }} 2,015$ maka dapat disimpulkan bahwa tidak ada hubungan yang signifikan antara factor fisik kimia lingkungan dengan dominanasi echinodermata.

\section{DAFTAR PUSTAKA}

Angreni F, Litaay M, Priosambodo D, Moka W. (2017). Struktur komunitas echinodermata di padang lamun pulau tanakeke kabupaten takalar sulawesi selatan. Bioma: Jurnal Biologi Makassar. 2(1) 46-55, 2017 Departemen Biologi FMIPA UNHAS. Online, diakses 10 April 2019.

Arifah D, Santoso H, Noor R. (2017). Indeks Keanekaragaman Echinodermata di Pantai Tanjung Setia Kabupaten Pesisir Barat Sebagai Sumber Belajar Biologi SMA Kelas X. BIOEDUKASI Jurnal Pendidikan Biologi VOL 8. NO 2 NOV 2017. e ISSN 2442-9805 Universitas Muhammadiyah Metro p ISSN 2086-4701.

Nyabakken, James. Wiley. (1988). Biologi laut, suatu pendekatan biologi. Jakarta. Gramedia.

Romimohtarto \& Juawana S. (1999.) Biologi Laut. Djambatan. Jakarta.

Rumahlatu D. Gofhur A, Sutomo H. 2008. Hubungan factor fisik-kimia lingkungan dengan keanekaragaman echinodermata pada daerah pasang surut pantai Kairatu. Jurnal MIPA, tahun 3. No 1 Januari 2008.

Suwartimah K, Wati D S, Endrawati H, Hartati R. (2017). Komposisi Echinodermata Di Rataan Litoral Terumbu Karang Pantai Krakal, Gunung Kidul, Yogyakarta. Buletin Oseanografi Marina April 2017 Vol 6 No 1:53-60. ISSN: 2089-3507

Yusron E. (2010). Keanekaragaman Jenis Echinodermata di Perairan Likupang, Minahasa Utara, Sulawesi Utara. Ilmu Kelautan Juni 2010. vol. 15 (2) 85-90. ISSN 0853-7291 